\title{
Estudo epidemiológico da violência por arma branca no município de Porto Grande, Amapá*
}

\author{
Epidemiological study of the violence with knives in \\ the county of Porto Grande, Amapá, Brazil
}

José M aria Ximenes Guimarães 1

Evaldo Eufrásio Vasconcelos 1

Rejane Santos da Cunha 1

Ronaldo Dantas de M elo 2

Luiz Felipe Pinto 3

\footnotetext{
1 Programa de Interiorização do Trabalho em Saúde, PITS/M S, Secretaria M unicipal de Saúde de Porto Grande. Rodovia Perimetral N orte, $\mathrm{s} / \mathrm{n}, 68997-000$,

Porto Grande AP joseximenes.guimaraes@ bol.com.br

2 Secretaria de Estado

da Saúde do Amapá

3 Departamento de

Ciências Sociais, Escola

Nacional de Saúde Pública,

Fiocruz. Rio de Janeiro.

Fundação Educacional

Serra dos Órgãos. Centro

de Ciências Biomédicas.

Curso de Graduação de

Medicina.

*Artigo extraído da monografia "Estudo epidemiológico da violência por arma branca no município de Porto Grande, Amapá", apresentada à Universidade Federal do Amapá.
}

Abstract The study aproaches the violence problem, especially violent events with cutting weapon. It is a survey with the objects of analyzing epidemiological aspects present on those cases of violence with cutting weapon on the urban area of the county of Porto Grande - Amapá. The sample considered 50 victims of violence with cutting weapon and the collection of the database happend through secondary source, on the entry books of the Police Station and Emergency Service of "U nidade M ista de Saúde". In addition it was used one tool to get the data in field. It was found that the biggest incidence of violence with cutting weapon was among men, especially, young men and teenagers, both single. It's true that the most victims has low degree, and low socieconomic level, a population of "leisured". The places that had the biggest ocurrence of the events was: the public route and pubs, dance clubs and alikes. It's also stressed the faults on the registry of information related to violence on the institutions. One possible explanation of the events is the poverty, social exclusion, and the group fun drink-alcohol-violence, in this particular case.

Key words White weapon, Violence in health, External cause morbidity
Resumo 0 estudo aborda a problemática da violência, em particular os eventos violentos com uso de arma branca. Denatureza transversal, tem o objetivo de analisar os aspectos epidemiológicos nos casos de violência por arma branca ocorridos na zona urbana em Porto Grande (AP). A amostra considerou 50 vítimas de violência por arma branca, ea coleta de dados ocorreu através de fonte secundária, constituída pelos livros de registros da Delegacia de Polícia e do Serviço de Emergência da Unidade M ista de Saúde. Em caráter adicional, foi aplicado um instrumento de coleta de dados em pesquisa de campo. Os achados revelaram que a maior incidência de violência envolvendo o uso de arma branca encontra-se entre os homens, representados principalmente por adultos jovens e adol escentes, ambos solteiros. Constatou-se ainda que a maioria das vítimas possui baixo grau de escolaridade e baixo poder aquisitivo, visto que é constituída por uma população de "desocupados". Os locais de maior ocorrência dos eventos foram: a via pública e bares, boates e similares. Destaca-se também a existência de faIhas nos registros de informações relacionadas à violência nas instituições. Como possíveis explicações para a presença destes eventos violentos aparecem a pobreza, a marginalidade e a exclusão social, além da tríade lazer-bebida alcoólicaviolência, neste caso em particular.

Palavras-chave Arma branca, Violência em saúde, M orbidade por causas externas 


\section{Introdução}

A violência nas suas mais variadas formas de manifestação, em virtude de sua tendência crescente, vem sendo referida nos últimos anos como um grave e relevante problema em diversos países, inclusive no Brasil.

Para Almeida (2000), a problemática da violência tem realmente causado preocupação no mundo inteiro, sobretudo aos profissionais envolvidos no atendimento dos seus efeitos, assim como do seu elevado número de vítimas. Ressalta ainda que a mesma já está inserida no cotidiano da população urbana e seus efeitos representam uma importante causa de mortalidade.

No Brasil, segundo Silva et al (1997), foi a partir de 1985, com o processo de redemocratização do País, que o problema da violência ganhou status de problema nacional. Para eles este fato está relacionado aos desajustes sociais que passaram a afetar cada vez mais as camadas sociais mais privilegiadas. A partir de então as atenções se voltaram para a delinqüência das camadas mais baixas e a violência passou a ser considerada fenômeno urbano.

0 fenômeno da violência sempre foi tratado com maior ênfase no setor das ciências jurídicas e sociais, mas nos últimos anos vem se constituindo um sério problema de saúde pública, não só pelos danos físicos e psíquicos que ocasiona, mas também pelo número de óbitos em sua decorrência (Freitas et al., 2000). Acredita-se que sua inserção no contexto do setor saúde não esteja relacionada somente aos danos físicos causados e até mesmo às seqüelas deixadas, havendo aí a necessidade de intervenção médica e biomédica, mas também ao elevado ônus de custear a assistência nas emergências hospitalares e também com internações das vítimas da violência, que apesar de não se ter estudos que quantifiquem estes custos com precisão, empiricamente pode-se afirmar que são elevados.

Apesar de a Classificação Internacional das Doenças (CID) da Organização M undial de Saúde/OMS ter incluído, há anos, nos seus códigos o problema da violência em um grupo chamado "causas externas", durante muito tempo o setor saúde pareceu olhar a violência de forma indiferente ou como mero catalisador dos danos por ela causados às pessoas, ou ainda como mero contador dos eventos violentos em que as vítimas procuravam os serviços de saúde (M inayo \& Souza, 1999). Por outro lado, segundo as mesmas autoras, a partir da década de 1960 essa postura começa a mudar, quando os pediatras dos Estados Unidos começam a estudar, diagnosticar e tratar a chamada síndrome do bebê espancado - síndrome de Caffey. M ais tarde, nos anos 70, outros países também passam a entender os maus-tratos como um problema de saúde pública. D esde então, inicialmente no Estados U nidos, em seguida em outros países, começam a ser criados também programas nacionais de prevenção primária e secundária da violência, além de centrais de denúncias.

No Brasil, passou-se a observar uma preocupação maior com a problemática da violência no setor saúde a partir da década de 1980, atingindo seu apogeu no ano de 2001, quando se vê, mais proeminente, a elaboração de políticas públicas voltadas para a questão, com a publicação da portaria no 737 M S/GM, de 16 de maio de 2001, que estabelece a Política N acional de Redução da M orbimortalidade por Acidentes e Violências. Esta portaria visa reduzir a morbimortalidade por acidentes e violências no Brasil, mediante o desenvolvimento de ações articuladas e sistematizadas (Brasil, 2001). Além disso, houve a implantação de Grupos de Atividade e M onitoramento de Agravos por Fatores Externos em alguns Estados brasileiros, sendo o Amapá um dos pioneiros; a criação de Comitês de Prevenção de Acidentes e Violências na Infância e na Adolescência; e por último a aprovação pelo Congresso $\mathrm{N}$ acional do Estatuto do desarmamento, dentre outras ações, que prevê, para outubro de 2005 um referendo popular sobre o fim da comercialização de armas no País.

Não obstante a essa nova conduta diante da problemática, dados da OM S revelam que no ano 2000 ocorreu 1,7 milhões de mortes em decorrência de violência em todo mundo, sendo que aproximadamente um terço foi homicídios, e um quinto decorrente de conflitos armados, o que nos faz consolidar a percepção da violência como um dos mais sérios problemas de saúde pública em todo o mundo e que ainda está distante de ser solucionado ou pelo menos amenizado (OM S, 2001).

A partir da década de 1980 as mortes por violência e acidentes tiveram uma tendência ascendente no Brasil, onde passaram da quarta para a segunda causa de mortalidade no País perdendo somente para as causas cardiovasculares; inclusive constituem a primeira causa na faixa etária de 5 a 39 anos, sendo que as mortes por violência superam as acidentais. 
Por outro lado, um estudo realizado por Silva (2000), com dados de treze Estados brasileiros sobre homicídios nos anos de 1997 e 1998, revelou que quanto à incidência por tipo de arma em primei ro lugar está a arma de fogo (78,31\%), seguido da arma branca ( $10,96 \%)$.

Evidencia-se que apesar de existirem no Brasil fontes oficiais de informação sobre a violência, dentre as quais destacam-se as Secretarias de Segurança Pública e as Secretarias Estaduais e M unicipais de Saúde, o evento violento é pouco esclarecido tanto por parte da polícia quanto pelos serviços de Saúde. A ausência em ambas as instituições de dados necessários para 0 esclarecimento dos eventos violentos pode ser fruto da carência de formulários específicos ou do mau preenchimento destes, não só pela precariedade da investigação, como por falta de interesse ou descaso. Enfim, as informações são desqualificadas, portanto perdem seu potencial analítico (Njaine et al., 1997).

Não obstante este problema, observa-se uma exploração "abusiva" dos eventos violentos pela mídia, muitas vezes limitando-se a uma divulgação sensacionalista, banalizan do um tema sério e que necessita de uma abordagem científica que venha a contribuir para a sua compreensão, além de fornecer subsídios para intervenções eficazes e intersetoriais, no sentido de resolver ou pelo menos amenizar os impactos resultantes do problema.

Para abordar a questão da violência e sua repercussão, na perspectiva do setor saúde, fazse necessário antes de tudo compreender que este fenômeno constitui também um problema de saúde pública, em decorrência da elevada morbidade e mortalidade por esta causa. Constata-se esta realidade ao consultar dados disponíveis no Datasus referentes à morbimortalidade, sendo que aparecem na Classificação Internacional de Doenças, na sua 10a revisão (CID10), a partir de 1998, sob a denominação de causas externas, nas quais são agrupadas as mortes por acidentes, violências, envenenamentos e afogamentos.

A pesar de a violência ser um fenômeno de conceituação complexa e da multiplicidade de fatores envolvidos, este trabal ho trata o fenômeno como sendo o uso agressivo da força física de indivíduos ou grupos contra outros, sendo que a possibilidade ou ameaça de usá-la constituem dimensão relevante da sua natureza e socialmente nenhum indivíduo ou grupo está isento de sofrer alguma forma de violência (VeIho, 1996).
É notório que a violência vem aumentando nos últimos anos nos centros urbanos, com acréscimo também do número de atendimentos de vítimas da mesma nos serviços de emergência, assim como do número de hospitalizações, o que é confirmado por M inayo e Souza (1999) quando afirmam que, a partir dos anos 80 , as violências passaram a ocupar o segundo lugar no perfil de mortalidade, sendo os jovens do sexo masculino cada vez mais atingidos pelas violências, seja como vítimas seja como autores. Também o IBGE (2003) ressalta que as mortes violentas atingem com mais intensidade a população-residente da região Sudeste. Para o País com um todo, a taxa de mortalidade daqueles entre 15 e 29 anos, por exemplo, é de 175 mortes por 100 mil habitantes, chegando a 224 mortes por 100 mil habitantes no Sudeste, com o Rio de Janeiro aparecendo em primeiro lugar, com taxa de 285 mortes por $100 \mathrm{mil}$ habitantes, seguido de Pernambuco $(273,3)$ e São Paulo $(260,2)$.

0 problema da violência, nas suas mais variadas formas, envolve aspectos que extrapolam a esfera de competência do setor saúde. Porém não é difícil perceber que é sobre este que recai o maior ônus do problema, visto que é ele quem recebe e trata diariamente as vitimas, sobrecarregando o setor, que, há muito, luta por melhor política de financiamento e por maior aporte de recursos tecnológicos.

Diante da magnitude do problema, a Política N acional de Redução da M orbimortalidade por Acidentes e Violências, proposta pelo $\mathrm{M} \mathrm{i-}$ nistério da Saúde em 2001, refere como princípio norteador que a promoção da saúde deve embasar todos os planos, programas, projetose atividades de redução da violência (Brasil, 2001), porém ainda se encontra em fase de sensibilização para a problemática e implantação de programas de prevenção da violência em alguns Estados brasileiros.

A pesar das inúmeras formas com que a violência é praticada, este estudo limita-se aos casos de violência em que ocorreu lesão corporal devido ao uso de arma branca. A secretaria da Justiça e da Segurança do Rio Grande do Sul, referindo o decreto federal no 3.665/00 (R-105), considera como arma branca todo objeto perfurocortante, constituído por peças em lâmina ou oblonga. Refere ainda que segundo a doutrina e jurisprudência para efeito de caracterização de contraven ção, vários objetos são reconhecidos como arma branca, dentre outros, as bengalas, sprays de gás, cassetetes, navalhas, 
facas, facões, soco inglês (Rio Grande do Sul, 2001).

0 interesse por este tema é fruto da observação freqüente de atendimento a vítimas de lesão por arma branca no serviço de emergência da U nidade M ista de Porto Grande (AP). Trata-se de um município de pequeno porte, entretanto visualizou-se um considerável número de vítimas, al gumas fatais, no referido serviço. Isto gerou inquietações no sentido de compreender a(s) causa(s) e/ou fatores presentes na problemática abordada. N este sentido, seguem os propósitos deste estudo vislumbrando elucidar estas inqui etações e também contribuir cientificamente na produção de conhecimento sobre o tema aqui apresentado. Para isso, pretendemos analisar alguns aspectos epidemiológicos presentes nos casos de violência por arma branca ocorridos na zona urbana do município de Porto Grande.

\section{Material e métodos}

0 estudo é de natureza transversal, com cunho exploratório descritivo e uma abordagem quantitativa. Foi realizado no período de fevereiro a agosto/2003, quando foram analisados dados referentes ao período de março/2002 a março/2003 (13 meses). N este estudo o foco está em aspectos relacionados à vítima.

0 universo do estudo é constituído pelas vítimas de violência por arma branca no município de Porto Grande (AP), e que foram atendidas na unidade mista e/ou registraram ocorrência na polícia do município no período determinado para o estudo. Entretanto, a amostra é composta por 50 vítimas, sendo que o critério utilizado de inclusão considerado relaciona-se ao fato de a agressão ter ocorrido na zona urbana.

Os dados foram coletados no período de maio a junho, através de fontes de dados secundárias, constituídas pelos livros de registros de ocorrência da emergência da U nidade M ista deSaúde e da D elegacia de Polícia. D evido à inconsistência de registros, que apresentam também escassez de dados, foi preciso optar por uma fonte primária: um questionário com perguntas abertas e fechadas. Este foi aplicado aos participantes após a identificação dos mesmos nos livros de registros supracitados. Para localizar essas vítimas, contou-se com a colaboração de pessoas da própria comunidade e também dos agentes comunitários de saúde, que foram treinados para aplicação do questionário. Os entrevistados eram informados dos objetivos do estudo e forneciam seu consentimento livre e esclarecido, ficando então ciente de que sua identidade seria mantida em sigilo, e que poderia desistir da participação a qualquer momento da entrevista. As informações coletadas seriam utilizadas somente para a pesquisa em questão, e a futura necessidade por acesso aos serviços de saúde do município, não sofreria qualquer prejuízo.

\section{0 local de estudo}

0 estudo foi realizado no município de Porto Grande, situado na parte central do Estado do Amapá, com uma extensão territorial de 4.402 $\mathrm{km}^{2}$, sua sede dista $115 \mathrm{~km}$ da capital do Estado. Foi criado em 1o de maio de 1992, fazendo fronteira com o município de Ferreira Gomes ao norte; ao leste, com M acapá (capital), M azagão e Santana ao Sul; e ao oeste com Pedra Branca do Amaparí.

A principal via de acesso para a capital e para os municípios vizinhos (Pedra Branca, Serra do N avio eFerreira Gomes) éa rodovia BR-156, asfaltada somente no trecho M acapá - Porto Grande, o que faz com que o meio de transporte mais utilizado seja o rodoviário, embora seja usado também o ferroviário al guns dias da semana quando o trem faz o percurso Serra do N avio - Santana, passando pelo município.

Segundo o IBGE, o município conta com uma população de 12.828 habitantes, o que representa uma densidade demográfica total de apenas 2,9 hab./km2. A taxa de crescimento anual da população no período de 1996-2000 foi da ordem de $11,31 \%$, bem maior do que a do Estado que é $5,82 \%$ e muito maior que a do País como um todo, que foi de $1,67 \%$ nesse período. Acredita-se que o fluxo migratório decorrente principalmente do extrativismo mineral, presente no município, muito contribui para esta taxa el evada. Q uanto ao sexo, 6.972 $(54,3 \%)$ indivíduos são do sexo masculino e $5.856(45,7 \%)$ do sexo feminino, gerando, portanto, uma razão de sexos de 119:1, ou seja, para cada grupo de 100 mulheres há cerca de 120 homens. A maior concentração populacional está na área urbana com cerca de $67 \%$ da população.

Quanto à hidrografia, o município é banhado pelos rios Amaparí, Araguari eVila Nova e de alguns riachos. Os mesmos têm impor- 
tância cultural e econômica, sendo a pesca um item relevante. A base econômica de maior expressão no município é a exploração da madeira, estando presente também a atividade agrícola, gerando produtos para a comercialização e para a subsistência. Há também o extrativismo mineral, principalmente de seixo, pedras e areia para a construção civil, além de ouro e outros minerais de importância econômica como a cassiterita e a cromita, representando forte elemento de influência nos fluxos migratórios.

Com relação às atividades de turismo e lazer, estas se concentram principalmente nos balneários existentes e no festival anual do abacaxi, que acontece no mês de setembro. Ressalta-se que nos finais de semana a população também tem como lazer os diversos bares espalhados, assim como a praça localizada no centro da cidade, onde há também dois bares.

O município possui em sua estrutura educacional 22 escolas de ensino fundamental e apenas uma de ensino médio. Estima-se que cerca de $81,6 \%$ da população acima de 10 anos de idade seja alfabetizada (IBGE, 2000).

No setor saúde, o município encontra-se habilitado na G estão Plena da Atenção Básica, segundo a N orma O peracional Básica/96. Está estruturado com uma unidade mista, que possui 18 leitos, propondo-se a prestar atendimento na clínica médica, pediátrica, gineco-obstetra e cirúrgica. $A$ atenção básica conta com uma unidade básica na sede e cinco na zona rural. 0 setor de endemias conta com um posto de notificação na sede e dois no interior, todos funcionando com o serviço de microscopia para pesquisa de plasmódio, já que o município está inserido numa área considerada de alto risco para se contrair ou morrer por malária, segundo dados da Fundação N acional de Saúde. Entretanto, o município é desprovido de outros serviços de apoio diagnóstico. Quanto aos recursos humanos de nível superior, existem três médicos, um odontólogo e cinco enfermeiros, sendo apenas um contratado pelo Estado e quatro do Programa de Interiorização do Trabalho em Saúde (PITS). O Programa de Agentes Comunitários de Saúde - PACS foi implantado em 1997 e atua com 19 profissionais.

Atualmente a segurança pública está estruturada com uma Delegacia da Polícia Civil e uma da Policia M ilitar. A primeira tem um contingente de onze profissionais, sendo um delegado, dois escrivães, dois agentes de polícia, quatro guardas de presídio, um agente admi- nistrativo e um motorista; e tem uma viatura. A segunda tem um quantitativo de trinta policiais e duas viaturas.

Gregis (2002) ao referir dados do Sistema de Informação de M ortalidade (SIM) aponta que, no Estado do Amapá, a morte por causas violentas constitui a principal causa de mortalidade, com uma tendência crescente a partir de 1997. 0 autor lembra ainda que segundo 0 boletim estatístico de mortalidade por causas externas, produzido pelo Grupo de Atividadee M onitoramento de Agravos por Fatores Externos da Secretaria de Saúde do Estado do Amapá, mais de $50 \%$ das mortes por causas externas são relacionadas à arma de fogo e arma branca. No momento, parece pertinente lembrar que até agora se enfatizou bastante a questão da mortalidade em decorrência da violência, isto se justifica pelo fato destas informações estarem mais acessíveis. No que se refere às informações sobre morbidade por esta causa há uma certa "indisponibilidade" ou por não serem produzidas adequadamente ou por não serem devidamente divulgadas. No caso de Porto Grande, por exemplo, o registro sobre morbidade por causas violentas é feito apenas no livro de ocorrências da emergência da unidade mista, no qual, na maioria das vezes, é registrado apenas o nome da vítima atendida e o procedimento executado; não descreve claramente o tipo de lesão e as circunstâncias na qual foi provocada, tornando difícil a diferenciação, ao analisar os dados, entre lesão por violência de lesões por outras causas. No caso da delegacia de polícia os registros de ocorrência, muitas vezes, limitam-se ao nome da vítima e a uma breve descrição sobre a ocorrência.

\section{Enfrentando o problema da violência na perspectiva da Estratégia de Saúde da Família}

A Estratégia de Saúde da Família, proposta pelo M inistério da Saúde, objetiva a reorganização da atenção básica à saúde, na perspectiva da promoção da saúde e da prevenção de agravos. É, portanto, uma estratégia de vigilância à saúde. Dessa forma, o foco de atenção à saúde desloca-se do ser biológico, com as ações centradas na clínica médica, para o grupo familiar e a comunidade, novo campo de atuação desses profissionais, vislumbrando o fortal ecimento destes no enfrentamento de seus problemas de saúde (Gregis, 2002). 
Partindo desses princípios, observa-se que essa mudança de atenção contempla o proposto pela $\mathrm{Carta}$ de $\mathrm{Ottawa}$, no que diz respeito à promoção da saúde, ao afirmar que esta é um processo de capacitação da comunidade para atuar na melhoria da sua qualidade de vida e saúde, incluindo uma mai or participação no controle deste processo (Brasil, 1996).

No que se refere ao problema da violência, é perceptível que os profissionais que atuam no saúde da família ocupam uma posição favorável quanto à possibilidade de detectar os possíveis fatores de risco, assim como traçar planos de ação preventiva no setor saúde, justamente por atuarem em área adstrita e estarem inseridos na comunidade, ou seja, mais próximos do contexto sociocultural do qual as famílias fazem parte.

Por outro lado, não se percebe uma atuação efetiva desses profissionais no desenvolvimento de ações voltadas para o controle e/ou prevenção do problema em questão. Vários fatores podem estar dificultando a ação dos profissionais no que diz respeito à abordagem e encaminhamento adequado dos casos de violência. Dentre estes fatores pode-se apontar a falta de uma linguagem e de conceitos que reúnam o conhecimento médico ao de outras áreas afins ao problema, como a jurídica e a social, o que reflete no despreparo dos profissionais para a abordagem adequada ao paciente vítima de violência (Brasil, 2002).

Além disso, a Política Nacional de Redução da M orbimortalidade por A cidentes e Violência, proposta pelo M inistério da Saúde em 2001 (Brasil, 2001), apesar de referir como propósito que a promoção da saúde deve embasar todos os planos, programas, projetos e atividades de redução da violência e dos acidentes, não deixa bem definidas as atribuições dos profissionais envolvidos no Programa Saúde da Família nesse processo. Porém, ao se conceber a estratégia de saúde da família como fundamental no processo de vigilância à saúde no sentido de promovê-la e prevenir agravos, assim como prestar assistência no nível primário, pode se dizer que compete também aos profissionais que atuam nesta estratégia 0 atendimento às vítimas da violência, respeitando as limitações técnicas e estruturais, ou seja, de materiais e equipamentos das equipes.

Reconhecendo que diante da complexidade do problema da violência, as ações do setor saúde sofrem limitações, acredita-se que atuar na promoção e prevenção do problema exige dos profissionais envolvidos no Programa Saúde da Família, além de conhecimentos técnicos e científicos, uma postura de mobilizadores sociais, no sentido de buscar parceiros que possam atuar diante da problemática, promovendo assim a intersetorialidade, visando prestar uma assistência holística à vítima de violência, ou seja, exige que estes assumam uma postura mais abrangente, percebendo e respeitando as peculiaridades culturais, e apoiando as necessidades individuais e coletivas para uma vida mais saudável, abrindo canais entre o setor saúde e os setores sociais, políticos, econômicos e atémesmos ambientais, conforme o proposto na Carta de Ottawa, ao definir a promoção da saúde.

\section{Resultados}

Durante 0 estudo foram encontrados 52 registros referentes a eventos violentos com uso de arma branca na Delegacia de Polícia Civil do município e 36 na Unidade M ista de Saúde, sendo que somente sete casos constavam em ambas as instituições, o que leva a um total de 81 episódios de violência com uso de arma branca registrados no período de março/2002 a março/2003. Entretanto, trabalhou-se apenas com uma amostra de 50 casos, sendo o critério para seleção o fato de as vítimas terem sofrido a agressão na zona urbana do município.

Os eventos violentos por arma branca representavam nesse período $45,3 \%$ do total de ocorrências registradas na Delegacia de Polícia Civil do município de Porto Grande, superando todos os demais tipos de eventos, como ameaça/lesão por arma de fogo, espancamento, tentativa de estupro, acidentes de trânsito e suicídio, por exemplo. Se analisarmos os óbitos por causas externas ocorridos nessa mesma época, poderemos constatar que também aqui, o maior causador de mortes, responsável por $40 \%$ do total de óbitos registrados no município são as lesões oriundas de arma branca, seguidas pelas lesões por arma de fogo (20\%), acidente de trânsito (20\%) e afogamento (20\%).

Vislumbrando conhecer o perfil da população estudada, determinamos a distribuição por sexo e faixa etária, objetivando verificar a existência ou não de correlação entre estas variáveis e a casuística da violência em Porto Grande.

O bserva-se um predomínio de pessoas do sexo masculino ( $90 \%$ ) e maior incidência na faixa etária de 20 a 24 anos (40\%), seguida pelas faixas de 15 a 19 anos (24\%), de 25 a 30 anos 
(16\%) e de 31 a 39 anos (10\%), perfazendo uma média de 26 anos. Assim, com base nestes dados, pode-se afirmar que a violência atinge com maior intensidade os adolescentes e mais ainda os adultos jovens.

Quanto ao Estado de origem, as vítimas de agressão por arma branca no município de Porto Grande são, na grande maioria, oriundas do Amapá ( $76 \%$ ), sendo que apenas $24 \%$ são procedentes de outros Estados como Pará e M aranhão.

Em relação ao estado civil, observa-se uma maior participação de solteiros, com 34 vítimas (68\%), seguida dos que vivem em união estável com 15 vítimas (30\%), e por um casado (2\%). Possivelmente essa maior expressão de solteiros pode esta relacionada à idade dos mesmos, visto que se observou também que $24 \%$ dos casos estão na faixa etária de 15 a 19 anos, fase em que muitas vezes ainda não têm projetos de vida concretos. Acredita-se também que a menor freqüência de vítimas em união estável e casados se deve ao fato destes já possuírem um projeto de vida em conjunto, em que se envolver em eventos desta natureza levaria a perdas maiores inclusive para a família.

Ao se investigar o perfil das vítimas, no que diz respeito ao grau de escolaridade, observouse que $14 \%$ são analfabetas, $24 \%$ alfabetizadas e $36 \%$ possuem apenas o 1o grau incompleto. A população com um grau de escolaridade mais elevado, 10 grau completo, 20 grau completo e incompleto, representa apenas $26 \%$, não tendo sido encontrado nenhuma vítima com nível superior. Este panorama de baixa escolaridade pode inclusive refletir na al ta taxa de desocupados, o que possivelmente tem como conseqüência 0 aumento da pobreza e da miséria.

Q uanto à atividade laboral das vítimas, ou seja, sua ocupação principal, evidenciou-se que esta é bastante diversificada, porém são ocupações desprovidas de status social. Chama a atenção o elevado número de vítimas sem ocupação (46\%), mostrando que a ociosidade contribui, neste caso, expressivamente para o aumento da violência. Este pensamento se solidifica quando Lima eXimenes (1998) afirmam que os processos sociais tais como a marginalidade e o desemprego, em razão da sua estrutura, contribuem para a explicação da violência. $\mathrm{Ou}$ tro achado importante é o fato de $10 \%$ das vítimas encontradas serem profissionais vigilantes. Entretanto, os mesmos referiram no questionário aplicado que as agressões não ocorreram no local de trabalho. Este fato é preocu- pante, pois sabe-se, empiricamente, que estes profissionais se revestem de um pseudo-poder em virtude da sua condição profissional e até mesmo do porte físico requerido para tal ocupação. Além disso, portam arma (mesmo que seja um simples cassetete) durante o horário de trabal ho, o que possivelmente estaria influenciando na formação de uma personalidade ou postura violenta.

Analisando a renda da população em estudo, observa-se que $50 \%$ das vítimas vivem sem renda própria, 10\% com renda inferior a um salário e 34\% com um salário mínimo, o que totaliza $94 \%$ desta população e representa a condição miserável da mesma. Vivem, portanto, na pobreza e na exclusão, onde suas famílias são isoladas do amparo social. Este fato é comprovado quando, ao se investigar a principal ocupação das vítimas, $46 \%$ das mesmas referem não ter nenhuma ocupação laboral e 2\% referiram serem estudantes. Além do fato de que os "ocupados" têm uma renda que muitas vezes garante precariamente a sua subsistência conforme assinalado anteriormente.

Ao se analisar o motivo da agressão referido pelas vítimas, verifica-se uma variedade de motivos desencadeantes. Em $32 \%$ dos casos não foi informado especificamente o motivo ou uma única causa. Chama a atenção o fato de $18 \%$ destas vítimas terem referido como principal motivo da agressão o uso de bebida al coólica ou de drogas, o que denota uma forte relação entre violência, álcool e drogas.

Outro achado que chamou atenção éa questão da presença de causas passionais em $10 \%$ dos casos, o que reflete a possível infidelidade, principalmente nas relações entre os jovens que vivem a falta de confiança em suas relações, até mesmo a necessidade de manter sua "honra", ou se defenderem de acusações que supostamente degredam sua imagem. É também relevante o fato de $10 \%$ destes episódios serem em decorrência de dívidas, o que nos faz entender que o baixo poder aquisitivo em decorrência do desemprego e conseqüente falta de renda própria realmente poderia ser fator causal da violência. Constatamos através da pesquisa de campo, que motivos aparentemente simples ou dívidas de valores ínfimos podem motivar violência de conseqüências desproporcionais.

Apesar de o centro de Porto Grande não ser o bairro mais populoso, os dados revelam que $60 \%$ das agressões por arma branca aconteceram nessa localidade, o que poderia ser explicado pela existência de um considerável núme- 
ro de bares, um balneário e uma praça, locais nos quais toda a população do município procura diversão/lazer nos finais de semana, associando, muitas vezes esta atividade com 0 abuso de álcool. Assim, na explicação das causas das agressões no município está presente a tríade lazer-bebida alcoólica-violência, como uma de suas explicações.

Por outro lado, bairros como Aeroporto, com $24 \%$ dos casos e $M$ al vinas com $8 \%$, o registro de agressões por arma branca explica-se pela presença de diversos bares e boates, portanto também está presente a tríade acima referida. Além disso, existe ainda a rivalidade coletiva entre grupos de jovens, referida pelas próprias vítimas entrevistadas, o que também explica a problemática abordada.

Quanto ao local de ocorrência, observou-se uma maior incidência dos eventos violentos em locais como bares, boates e similares em $34 \%$ dos casos. $\mathrm{N}$ a via pública ocorreram $26 \%$ dos casos, $12 \%$ em balneários e $28 \%$ em outros locais. A maior incidência em locais de lazer está atrelada a ingestão de bebida al coólica nestes locais.

Pode-se constatar que a violência está presente de forma mais intensa nos finais de semana, sendo que a maior incidência de agressões por arma branca em Porto Grande ocorreu nos dias de sábado com $48 \%$ dos casos, seguido pelos domingos ( $22 \%$ dos casos) e sextas-feiras (20\%). Analisando-se ainda a distribuição temporal, percebeu-se a maior incidência no período noturno em $78 \%$ dos casos. Este fato reforça um elemento já abordado anteriormente, que é a relação entre álcool e violência, visto que nesses dias e horário ocorre o maior consumo de bebidas al coólicas, como uma opção de lazer. 0 que reforça também, neste caso em particular, a relação entre lazer e violência, visto que um considerável número de agressões ocorreu em locais de lazer e em virtude da ingestão de álcool nestes locais.

$\mathrm{N}$ o que tange às regiões do corpo lesadas, constata-se a predominância de lesões em regiões como membros, o que denota uma menor gravidade imediata da vítima, do ponto de vista clínico. Assim como lesões na cabeça, geralmente couro cabeludo, também revelam menor gravidade, pelo fato destas regiões não abrigarem órgãos vitais.

Por outro lado, apesar de a maioria das vítimas terem sido lesadas em regiões que abrigam órgãos vitais, as lesões não representaram gravidade, pois apenas $10 \%$ delas ao procurar o hospital foram submetidas à cirurgia, e 30\% ficaram de observação e/ou internados. As demais se submeteram apenas à sutura e/ou curativo simples, pois sofreram lesões superficiais, ou por tentar se defender da agressão ou ainda pelo fato de o agressor não conseguir atingi-lo mais severamente por não ter intenção de matar (Tabela 1).

\section{Discussão}

Vários estudos, em diversas capitais brasileiras, revelam maior incidência de lesões e óbitos em decorrência da arma de fogo, o que talvez seja justificado pelo maior aporte financeiro e pela presença do crime organizado em algumas. No caso de Porto Grande, apesar de ser uma cidade de pequeno porte localizada no interior do Estado do Amapá, a violência está presente e se manifesta nas suas mais variadas formas, porém a maior incidência é representada por aquela praticada com arma branca e tem como conseqüência mais drástica um significativo número de óbitos em decorrência de lesões.

Este aspecto talvez seja reflexo da pobreza na qual esta população vive mergulhada. Outro fator que também contribui para tal realidade é o fato deste tipo de arma poder ser adquirida facilmente no comércio, ou ser fabricada artesanalmente em casa, visto que qual quer objeto perfurocortante pode ser considerado arma branca (Teixeira, 2001). Este autor ainda aponta para a falta de mecanismos de controle da venda deste tipo de arma, principalmente facas, pois sua venda se dá em larga escala no comércio, podendo ser adquirida por qualquer pessoa. Por outro lado percebe-se, no cenário nacional, políticas de fiscalização e controle da venda de arma de fogo e, mais recentemente, a chamada política de desarmamento, como necessidade urgente em virtude dos elevados índices de violência praticada com este tipo de arma principalmente nos grandes centros urbanos.

Destaca-se que no período em estudo $40 \%$ dos óbitos por causas externas no município de Porto Grande se devem a lesões por arma bran$\mathrm{ca}$, atingindo princi palmente os adultos jovens, pessoas com menos de 40 anos. Este fato está em consonância com estudos nesta área real izados por vários autores, dentre eles Silva (2000) e Freitas et al. (2000). M inayo \& Souza (1999) também afirmam que grupos jovens são cada vez mais atingidos, seja como vítimas, seja co- 
mo autores. Sendo que este fato pode estar relacionado a conflitos e desigualdades sociais, à exclusão social e também à impunidade das infrações e delinqüência.

0 sexo masculino éo mais atingido pela violência, o que revela que este é um grupo mais exposto aos problemas sociais, além da "cultura machista" ainda predominante na sociedade, sobretudo nos locais menos desenvolvidos, de que o homem tem mais liberdade e além de ter sempre de "defender sua honra", o que o torna mais vulnerável.

Aqui, é válido ressaltar que se visualiza uma maior exposição à violência de indivíduos do sexo masculino, ainda na adolescência e adultos jovens, o que, por um lado, faz lembrar que isto também pode estar atrelado não só a problemas sociais, mas também a imaturidade destes e a ausência de projetos de vida bem definidos.

O fluxo migratório éoutro componenteque contribui significativamente para a elevada taxa geométrica de crescimento anual da população de Porto Grande, que é uma das maiores do Estado, neste caso em particular, pode-se dizer que também está relacionado com o aumento da violência no perímetro urbano de Porto Grande, principalmente em virtude da migração relacionada com a exploração mineral nos garimpos. Entretanto, esta realidade diverge da encontrada por Lima \& Ximenes (1998) no estudo sobre violência e morte no espaço urbano do Recife, no qual concluíram que não há associação entre violência e migração.

A baixa escolarização observada entre a população estudada não deve ser associada com a casuística da violência. Por exemplo, Gregis (2002 apud Zaluar \& Leal, 2001) refuta a relação de associação entre "menos escolarização mais violência", a partir da constatação dos maiores índices de escolarização no Rio de Janeiro que é também o Estado brasileiro com os maiores índices de criminalidade e de mortes violentas.

Constatou-se também que apesar de somente $18 \%$ referirem como motivo para agressão a ingestão de bebida alcoólica ou uso de drogas, na verdade $68 \%$ disseram ter ingerido bebida alcoólica antes da prática do episódio violento, o que pode ter levado a própria vítima a provocar 0 agressor, induzindo-o a prática do ato. Assim teríamos o que se pode chamar de vítima precipitante, termo utilizado por Wolfang ( 1958 - apud M inayo \& Deslandes, 1998) para caracterizar a vítima de violência que provocou primeiro o agressor. Ainda, segundo $\mathrm{Mi}$ nayo \& Deslandes (1998), é bastante complexo o fenômeno da violência e sua ligação com álcool e drogas, exigindo que o assunto seja tratado com instrumentos, conhecimentos eações que ultrapassem a mera representação e moralismo simplista.

\section{Considerações finais}

N este estudo constatou-se o caráter polissêmico e complexo, por vezes controverso, da violência, independente da área do conhecimento que a aborde. Contudo, foi possível caracterizá-la como um sério problema de saúde pública, apesar de a mesma não constituir um objeto exclusivo deste setor, exigindo assim subsí-

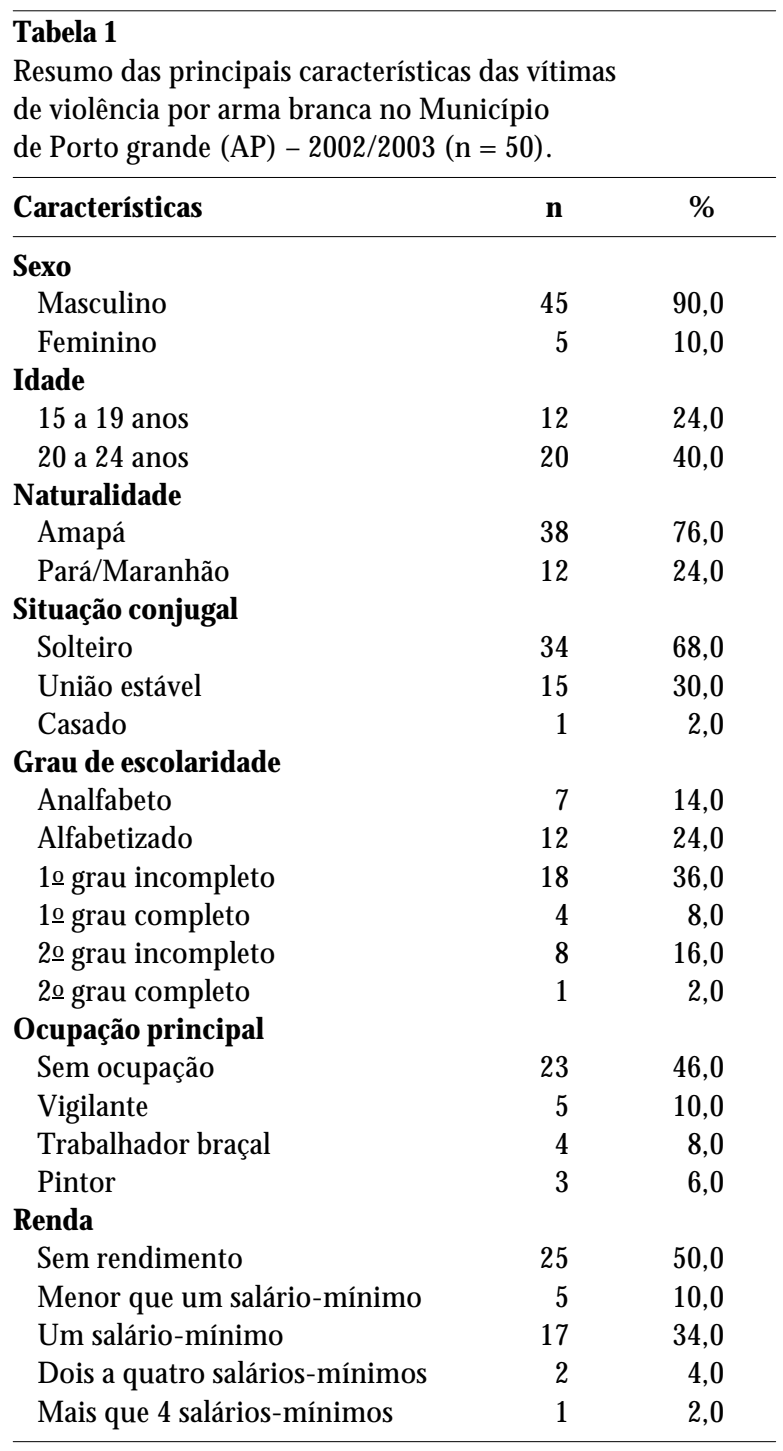

(continua) 


\section{Tabela 1 (continuação)}

Resumo das principais características das vítimas de violência por arma branca no M unicípio de Porto grande (AP) - 2002/2003 $(n=50)$.

\begin{tabular}{|c|c|c|}
\hline Características & $\mathbf{n}$ & $\%$ \\
\hline \multicolumn{3}{|l|}{ Motivo da agressão } \\
\hline Álcool/drogas & 9 & 18,0 \\
\hline Passional & 5 & 10,0 \\
\hline Dívidas & 5 & 10,0 \\
\hline Rivalidades coletivas & 4 & 8,0 \\
\hline Assalto & 4 & 8,0 \\
\hline Atividades sociais & 3 & 6,0 \\
\hline \multicolumn{3}{|l|}{ Bairro de ocorrência } \\
\hline Centro & 30 & 60,0 \\
\hline Aeroporto & 12 & 24,0 \\
\hline Malvinas & 4 & 8,0 \\
\hline Copalma & 2 & 4,0 \\
\hline Bobó & 1 & 2,0 \\
\hline Beira-Rio & 1 & 2,0 \\
\hline \multicolumn{3}{|l|}{ Local de ocorrência } \\
\hline Bares, boates e similares & 17 & 34,0 \\
\hline Via pública & 13 & 26,0 \\
\hline Balneários & 6 & 12,0 \\
\hline Outros $(*)$ & 14 & 28,0 \\
\hline \multicolumn{3}{|l|}{ Dia da semana } \\
\hline 2a a 5a feira & 5 & 10,0 \\
\hline 6ạ feira & 10 & 20,0 \\
\hline Sábado & 24 & 48,0 \\
\hline Domingo & 11 & 22,0 \\
\hline \multicolumn{3}{|l|}{ Região do corpo lesada } \\
\hline M embros superiores/inferiores & 18 & 36,0 \\
\hline Abdômen & 15 & 30,0 \\
\hline Cabeça & 14 & 28,0 \\
\hline Tórax anterior & 12 & 24,0 \\
\hline Pescoço & 7 & 14,0 \\
\hline Tórax posterior & 6 & 12,0 \\
\hline Outras regiões & 1 & 2,0 \\
\hline
\end{tabular}

Fonte: Questionário aplicado no campo.

(*) Inclui outros locais que aparecem de forma residual como campo, casa, local de trabalho. dios para sua compreensão e intervenções que extrapolam a esfera de competência da área da saúde.

Dentre as dificuldades de se realizar estudos sobre violência, destaca-se a falta de registros ou inconsistência destes nos órgãos responsáveis oficialmente pela atividade, no caso as Delegacias de Polícia e as U nidades de Saúde, referidas pelos pou cos estudiosos do assunto no Brasil, o que se confirmou na realidade do município onde este estudo foi realizado.

Evidenciou-se que as vítimas da violência por arma branca em Porto Grande, na sua maioria, são indivíduos adolescentes e adultos jo- vens, com baixo grau de escolaridade, sem renda própria, como conseqüência da elevada taxa de desocupados. As agressões ocorrem na maioria das vezes, nos finais de semana, em bares, boates e similares.

Os dados coletados e os achados na literatura permitem considerar que o fenômeno da violência tem relação direta com a marginalidade e a exclusão social. Além disso, também contribui para o aumento da mesma o uso abusivo de bebida alcoólica e de drogas. No caso de Porto Grande, em particular, observou-se uma associação desse problema de saúde pública com a tríade lazer-bebida al coólica-violência.

No Brasil, o setor saúde, apesar da dificuldade estrutural de lidar com a problemática da violência, seja por falta de uma linguagem e de conceitos que reúnam o conhecimento médico ao de áreas afins, seja pela falta de um melhor aparato tecnológico, em algumas situações, e de melhor política de financiamento, vem nos últimos anos tentando estabelecer ações mais abrangentes que visam à redução deste problema, como se percebe com a atual política de redução da morbimortalidade por acidentes e violências proposta pelo M inistério da Saúde.

Espera-se que estas ações não sejam isoladas, mas que consigam articular-se intersetorialmente visando à promoção de ambientes saudáveis, melhorias na qualidade de vida e saúde da população, além da capacitação da mesma no sentido de atuar efetivamente no controle deste processo, vislumbrando a redução deste mal que aflige a humanidade e suas conseqüências danosas, inclusive a ceifa de vidas prematuramente. Por outro lado, urgetambém a necessidade de interven ções eficazes na área social visando minimizar as desigualdades sociais. Algumas ações poderiam ser implementadas, tais como: a) realização de fóruns de discussão sobre a problemática da violência no município; b) sensibilização e capacitação dos profissionais de saúde para atuar de formar integral na abordagem à vítima de violência; $c$ ) criação de protocolos, nas unidades de saúde, para atendimento e registros adequados das informações, de forma unificada entre a del egacia de polícia e a unidade mista de saúde do município; d) articulação intersetorial, visando à criação de "ambientes saudáveis"; e) intervenções, na área social, visando a geração de emprego e renda. 


\section{Colaboradores}

JM X Guimarães participou de todas as etapas do trabaIho, sendo responsável pela estruturação do banco de dados, análise e revisão da literatura. EE Vasconcelos e RS Cunha, pela análise e coleta de dados. RD M elo e LF Pinto, pela concepção metodológica, análise dos dados e revisão da versão final.

\section{Agradecimentos}

Os autores agradecem à Coordenação do Programa de Interiorização do Trabalho em Saúde (PITS) do Amapá e também à Coordenação do Curso de Especialização em Saúde da Família da EN SP/Fiocruz, pela possibilidade de realização deste trabalho, quando da participação no Curso de Especialização em Saúde da Família na cidade de M acapá (AP).

\section{Referências bibliográficas}

Almeida HD 2000. Violência urbana: adolescentes em emergência pública, pp. 10-12. In Projeto Acolher: um encontro da enfermagem com o adolescente brasileiro. ABEn-Governo Federal, Brasília.

Brasil 1996. Promoção da Saúde: Carta de OTTAWA. Brasília, Distrito Federal.

Brasil 2001. Política N acional de Redução da M orbimortalidade por Acidentes e Violências: Portaria M S/GM oo 737 de 16/5/01 publicada no DOU no 96 seção $1 \mathrm{E}$, de 18/5/01. Brasília, Distrito Federal.

Brasil 2002. M inistério da Saúde. Violência intrafamiliar: orientações para a prática em serviço. Cadernos de Atenção Básica - no 8. Braślia.

Freitas ED et al., 2000. Evolução e distribuição espacial da mortalidade por causas externas em Salvador, Bahia, Brasil. Cadernos de Saúde Pública 16(4):1.059-1.070.

Gregis C 2002. Atuando na Atenção Básica à Saúde: as representações sociais da violência em Laranjal do Jarí. M onografia do Curso de Especialização em Saúde da Família. M acapá: Universidade Federal do Amapá.

Instituto Brasileiro de Geografia e Estatística (IBGE) 2000. Censo Demográfico de 2000. Disponível em <http:// www.ibge.gov.br>. Acessado em 16 de julho de 2003.

Instituto Brasileiro de Geografia e Estatística (IBGE) 2003. Síntese de Indicadores Sociais 2002. Departamento de População e Indicadores Sociais, Rio de Janeiro.

Lima M LC \& Ximenes R 1998. Violência e morte: diferenciais da mortalidade por causas externas no espaço urbano do Recife, 1991. Cadernos de Saúde Pública 14(4):829-840.

Minayo M CS \& Souza ER 1999. É possível prevenir a violência? Reflexões a partir do campo da saúde pública. Ciência \& Saúde Coletiva 4(1):7-32.
M inayo M CS \& Deslandes SF 1998. A complexidade das relações entre drogas, álcool e violência. Cadernos de Saúde Pública 14(1):35-42.

N jaine K et al. 1997. A produção da (des)informação sobre violência: análise de uma prática discriminatória. Cadernos de Saúde Pública 13(3):405-414.

Organización M undial de la salud (OM S). Violencia y salude. Consejo Ejecutivo - 109a Reunión, 2001. Disponível em <www.who.int/gb/EB_wha/PDF/EB109/ seb10915.-pdf>. Acessado em 9 de julho de 2003.

Rio Grande do Sul 2001. Instrução Complementar № 008/ $\mathrm{Ni}$ № 075/Bm/Embm/2001. Secretaria da Justiça e da Segurança, Porto Alegre.

Silva AAS 1997. A violência no cotidiano da cidade de M acapá (1991-1996). M onografia Curso de Graduação em História. M acapá, Amapá: Universidade Federal do Amapá, M acapá.

Silva JF 2000. Homicídios no Brasil: 1997 - 1998. M ovimento $\mathrm{N}$ acional de Direitos Humanos. Disponível em <www.dtnet.org.br/mnh/bdados/btxt1.htm>. Acessado em 27 de junho de 2003.

Teixeira PS 2001. Faca: uma arma ao alcance de todos. In A Gazeta, Rio Branco - AC. Disponível em <www. agazeta-acre.com.br/1607geral.htm>. Acessado em 27 de junho de 2003.

Velho G 1996. Violência, reciprocidade e desigualdade: uma perspectiva antropológica. In G Velho \& M Alvito (orgs). Cidadania e violência. UFRJ-FGV, Rio de Janeiro.

Artigo apresentado em 7/02/2004

Aprovado em 19/07/2004

Versão final apresentada em 2/08/2004 